\title{
Previous Caesarean Section; Subsequent Placenta Previa and its Outcome
}

\author{
Najma Bano Shaikh¹, Farah Naz², Farhana Shaikh³, Shahnaz Begum4, Shabnam Shaikh ${ }^{5}$ Samina Shaikh ${ }^{6}$ \\ 1,2,3,6Department of Gynecology \& Obstetrics, Liaquat University Hospital, Hyderabad-Pakistan, ${ }^{4}$ Department of Gynecology \& Obstetrics, BHU, Bahawal Zounr, Hyderabad-Pakistan, \\ ${ }^{5}$ Department of Gynecology \& Obstetrics, Hospital Shah Faisal Colony Korangi, Karachi-Pakistan
}

\section{ABSTRACT}

Background: Caesarean section rate is increasing in most countries. The relative risk for the placenta previa is higher in those having previous cesarean section as compared to those having an unscarred uterus. Objective: To observe the effects of placenta previa with previous Caesarean section on maternal and fetal outcome. Study Design: This was a prospective study. Settings: Obstetrics and Gynecology Department, Liaquat University Hospital, Hyderabad Pakistan. Duration: Six months from December 2016 to June 2017. Methodology: All pregnant having placenta previa and history of previous caesarean section at or $>28$ weeks of gestation irrespective of their parity and age were enrolled. Maternal and fetal outcome in terms of complications and mortality was observed. Data was collected via study proforma and analyzed by SPSS version 20. Results: Total 196 women were studied, their mean age was $29.19+2.66$ years and their mean gestational age was $35.44+2.44$ weeks. Morbidly adherent placenta was $5.10 \%$. Out of all $95.9 \%$ patients seen with antepartum hemorrhage and $86.7 \%$ underwent multiple blood transfusions. Postpartum hemorrhage was in $41.3 \%$ patients, renal impairment was in $25.5 \%$ patients, caesarean hysterectomy was done in $7.1 \%$ cases and maternal mortality was $1.5 \%$. Premature birth was $53.1 \%$ and $35.2 \%$ were admitted in NICU. Still birth rate was $27 \%, 17.9 \%$ cases were IUD, while fetal growth restriction rate was 14.3\%. Premature birth, still born, antepartum hemorrhage, Caesarean Hysterectomy and maternal mortality were significantly linked to high grade of placenta previa, $\mathrm{p}$-values were quite significant. Conclusion: Placenta previa with previous caesarean section remains risk factors for adverse maternal and fetal outcome. Efforts should be made to decrease this adverse outcome by spacing pregnancies, limitation of family size, proper antenatal care and early referral of high-risk patients.

Keywords: Placenta previa, Antepartum hemorrhage, Blood Transfusion, Caesarean section.

Corresponding Author

Submitted for Publication: 18-09-2019

Accepted for Publication: 20-06-2020

Dr. Najma Bano Shaikh, Assistant Professor, Department of Gynecology \& Obstetrics, Liaquat University Hospital, Hyderabad-Pakistan Email: najma.shaikh4@yahoo.com

Citation: Shaikh NB, Naz F, Shaikh F, Begum S, Shaikh S, Shaikh S. Previous Caesarean Section, Subsequent Placenta Previa and its Outcome. APMC 2020;14(1):272-6.

\section{DOI: 10.29054/APMC/2020.712}

\section{INTRODUCTION}

Placenta previa has been characterized as a placenta, which is located within lower uterine region entirely or partly. ${ }^{1}$ The precise reason of placenta previa remains unclear, however the related factors involve multiple gestation, drug abuse, high parity, older maternal age, smoking, and prior C-section. ${ }^{2}$ Placenta previa is typically diagnosed by clinical features however validated by ultrasound imaging. The $\mathrm{C}$-section rate is rising with each day in both industrialized and underdeveloped countries. The abdominal delivery rate in the USA, England and Latin America is $29 \%, 21.5 \%$ and $40 \%$ respectively. ${ }^{3}$

Due to good postoperative and preoperative treatment and prophylactic antibiotic coverage, likely linked to greater safety of $\mathrm{C}$-section in contemporary obstetrics. The risk factor for the growing prevalence of $\mathrm{C}$-sections is older maternal age, rising labor induction rate and declining usage of surgical vaginal delivery. Primary elective abdominal deliveries are also a major contributor, either by inclination or considered valuable for certain reasons. Maternal morbidity is increasing gradually, although with a growing rate of $\mathrm{C}$-sections with respect to scar dehiscence, dense adhesions, and risk of placenta previa and its pathological adherence. ${ }^{3}$ The prevalence of placenta previa is three times increased among females who had previous deliveries by caesarean sections, ${ }^{1}$ this frequency may significantly increase with increased numbers of previous cesarean sections as; around $16.36 \%$ in those having only one previous c-section and $66.67 \%$ among those having multiple caesarean sections. ${ }^{4}$

Placenta previa may have significantly adverse fetometernal effects, including an elevated risk of parental, postnatal and maternal death, preterm delivery, fetal growth suppression and intrapartum and antenatal hemorrhage and further blood transfusions. . $^{5-10}$ Scar uterus has been reported to be a predisposing factor for morbid adherence and also placenta accreta. This research would help to explore the current knowledge regarding impact of placenta previa as well as its morbid adherent on fetal outcome and maternal health at local level.

\section{METHODOLOGY}

Study Design: Prospective Observational study.

Settings: Obstetrics and Gynecology department, Liaquat University Hospital, Hyderabad Pakistan.

Duration: Six months from December 2016 to June 2017.

Sample Technique: Non-probability consecutive sampling.

Sample Size: Total 196 women were selected in the study. 
Inclusion Criteria: All the pregnant women having placenta previa with history of previous caesarean section at gestational age $\geq 28$ weeks either of age and parity were enrolled.

Exclusion Criteria: All the patients having abruptio placentae, uterine scar due to gynecological surgeries, chronic hepatitis, thrombocytopenia and history of smoking were excluded.

Data Collection Procedure: This study was conducted after taking ethical approval from ethical review committee of Liaquat University of medical and health Sciences. Informed written consent was taken from all the enrolled patients those fulfilling the inclusion criteria. After taking demographic information including age, parity, and number of previous caesarean section history, complete clinical examination was done and routine required laboratory investigations were done. All the patients underwent fresh ultrasound for the type of placenta previa and its types with its morbid adherence to uterine scars. Placenta previa was defined as the placenta that is situated entirely or partly in the lower uterine segment. Maternal outcome was defined as antepartum hemorrhage, blood transfusion, postpartum hemorrhage, Caesarean hysterectomy and maternal death. Fetal outcome was defined as premature birth, intrauterine death, still birth, fetal growth restriction and neonatal intensive care unit admission. All the data was recorded in the study proforma.

Data Analysis Procedure: Data was analyzed via SPSS version 20. Mean and standard deviation were computed for numerical data like age and gestational age. Frequency and percentage were computed for categorical variables. Chisquare test was applied and a p-value $\leq 0.05$ was considered significant.

\section{RESULTS}

Total 196 women having placenta previa with previous caesarean section were studied. Patients mean age was $29.19+2.66$ years and their mean gestational age was $35.44+2.44$ weeks. Mean of the previous caesarean section was $01.33 \pm 0.71$. Most of the women $95.9 \%$ had anemia. Table.1

Table 1: Descriptive statistics of demographic variables $(n=196)$

\begin{tabular}{|l|c|}
\hline \multicolumn{1}{|c|}{ Variables } & Statistics \\
\hline Patients age & $29.19+2.66$ years \\
\hline Gestational Age & $35.44+2.44$ weeks \\
\hline Number of previous C/S & $01.33 \pm 0.71$ \\
\hline Parity & $02.13 \pm 1.21$ \\
\hline Anemia & $188(95.9 \%)$ \\
\hline
\end{tabular}

According to the types of placenta previa, $38.27 \%$ women had placenta type I, followed by $29.08 \%$ diagnosed as placenta type II, type II was in $27.55 \%$ and placenta previa type VI was in $5.10 \%$ of the patients. Figure 1

\section{5}

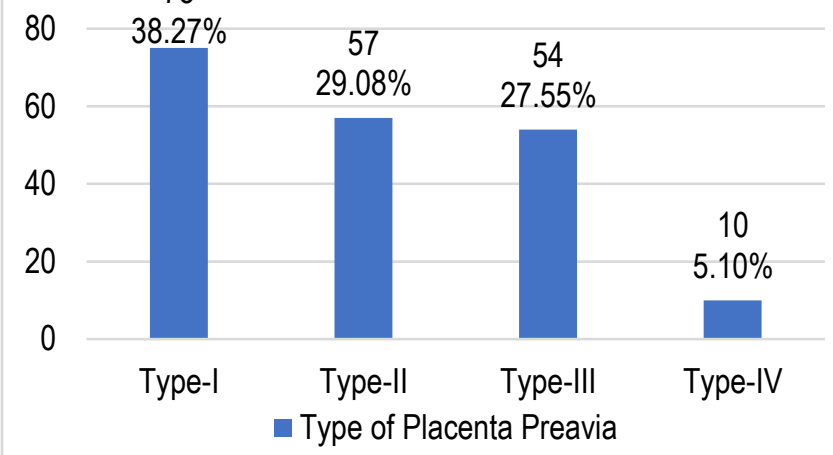

Figure 1: Types of placenta previa $(n=196)$

Out of all morbidly adherent placenta was found in $5.10 \%$ of the study participants. Figure 2

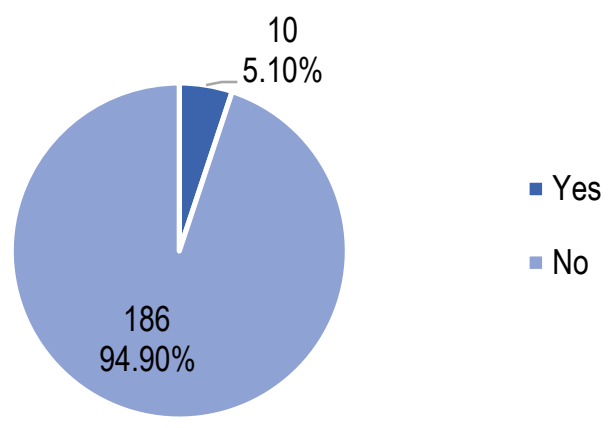

Figure 2: Morbidly adherent placenta in obstetrics patients $(n=196)$

According to the maternal outcome antepartum hemorrhage was frequently seen in $95.5 \%$ cases, and $86.7 \%$ women underwent blood transfusions, while postpartum hemorrhage was seen in $41.3 \%$ of the cases. Renal impairment was seen in $25.5 \%$ patients, caesarean hysterectomy was done $7.1 \%$ and maternal mortality was only $1.5 \%$. However antepartum hemorrhage was almost in all cases of placenta type II, III and IV $(p=0.004)$, while caesarean hysterectomy and maternal mortality were significantly higher in placenta type IV $(p=0.005)$. Table 2

Table 2: Maternal outcome according to types of placenta previa $(n=196)$

\begin{tabular}{|c|c|c|c|c|c|}
\hline \multirow{2}{*}{$\begin{array}{c}\text { Maternal } \\
\text { Outcome }\end{array}$} & \multicolumn{3}{|c|}{ Types of placenta previa } & \multirow{2}{*}{$\begin{array}{c}\text { - } \\
\text { Value }\end{array}$} \\
\cline { 2 - 5 } & $\mathbf{I}(\mathbf{n}=\mathbf{7 5})$ & $\mathbf{I I}(\mathbf{n}=57)$ & $\mathrm{III}(\mathbf{n}=54)$ & $\mathbf{I V ( n = 1 0 )}$ & $0.004^{*}$ \\
\hline APH & $67 / 89.3 \%$ & $57 / 100 \%$ & $54 / 100 \%$ & $10 / 100 \%$ & 0.00 \\
\hline PPH & $29 / 38.7 \%$ & $27 / 47.4 \%$ & $20 / 37.0 \%$ & $5 / 50.0 \%$ & 0.616 \\
\hline $\begin{array}{c}\text { Blood } \\
\text { Transfusion }\end{array}$ & $65 / 86.7 \%$ & $47 / 82.5 \%$ & $50 / 92.6 \%$ & $8 / 80.0 \%$ & 0.405 \\
\hline $\begin{array}{c}\text { Caesarean } \\
\text { Hysterectomy }\end{array}$ & 00 & $4 / 7.0 \%$ & $6 / 11.1 \%$ & $4 / 40.0 \%$ & $0.0005^{*}$ \\
\hline Renal Failure & $20 / 26.7 \%$ & $16 / 28.1 \%$ & $11 / 20.4 \%$ & $3 / 30.0 \%$ & 0.776 \\
\hline $\begin{array}{c}\text { Maternal } \\
\text { Death }\end{array}$ & 00 & 00 & $1 / 1.9 \%$ & $2 / 20.0 \%$ & 0.0005 \\
\hline
\end{tabular}

$\mathrm{APH}=$ Antepartum hemorrhage, $\mathrm{PPH}=\mathrm{Post}-$ partum hemorrhage 
According to the fetal outcome premature birth and admission in neonatal intensive care unit were commonest as $53.1 \%$ and $35.2 \%$ respectively, followed by still birth was seen in $27 \%$ of the patients and $17.9 \%$ were IUD, while $14.3 \%$ were IUGR. However premature births were significantly high in placenta previa type III and IV ( $p=0.007$ ), still birth was markedly high in type II, and NICU admission was significantly associated to placenta previa type IV ( $p=0.058)$. Table 3

Table 3: Fetal outcome according to type of placenta previa $(n=196)$

\begin{tabular}{|c|c|c|c|c|c|}
\hline \multirow{2}{*}{$\begin{array}{c}\text { Fetal } \\
\text { Outcome }\end{array}$} & \multicolumn{4}{|c|}{ Types of placenta previa } & \multirow{2}{*}{$\begin{array}{c}\text { P- } \\
\text { Value }\end{array}$} \\
\hline & $I(n=75)$ & II $(n=57)$ & III $(n=54)$ & $I V(n=10)$ & \\
\hline FGR & $7 / 9.3 \%$ & $12 / 21.1 \%$ & $8 / 14.8 \%$ & $1 / 10.0 \%$ & 0.284 \\
\hline Prematurity & $36 / 48 \%$ & $23 / 40.4 \%$ & $38 / 70.4 \%$ & $7 / 70.0 \%$ & $0.007^{*}$ \\
\hline $\begin{array}{c}\text { Intrauterine } \\
\text { Death }\end{array}$ & $13 / 17.3 \%$ & $7 / 12.3 \%$ & $12 / 22.2 \%$ & $3 / 30.0 \%$ & 0.403 \\
\hline Still Birth & $18 / 24.0 \%$ & $23 / 40.4 \%$ & $11 / 20.4 \%$ & $1 / 10.0 \%$ & $0.043^{*}$ \\
\hline $\begin{array}{c}\text { NICU } \\
\text { Admission }\end{array}$ & $28 / 37.3 \%$ & $23 / 40.4 \%$ & $12 / 22.2 \%$ & $6 / 60.0 \%$ & 0.058 \\
\hline
\end{tabular}

FGR= Fetal growth restriction

\section{DISCUSSION}

Placenta previa, correlated with elevated perinatal and maternal mortality and morbidity, is a major factor of obstetric hemorrhage. The mean age of the females in present study was $29.19 \pm 2.78$ years, and the females' mean gestational age was $35.10 \pm 2.38$ weeks. Likewise Bhuyar $S$ et al ${ }^{11}$ documented a mean age of $26 \pm 3.3$ years in their patients along with a mean gestational age of $36.9 \pm 2.7$ weeks on delivery. In present study, blood transfusion rate was high due to antepartum and postpartum hemorrhage. Ayaz et al ${ }^{12}$ stated that the probability of cumulative maternal morbidity among placenta previa females was considerably higher. Among the females with placenta previa, the likelihood of PPH, coagulopathy and blood transfusions was substantially higher. Rouse et $\mathrm{al}^{13}$ observed that, among females having placenta previa, high $\mathrm{C}$-section was correlated with a raised likelihood of transfusion. In the study of Silver et al ${ }^{14}$ further previous C-section was found to be correlated with a raised likelihood of complications, including need for frequent blood transfusions, prolonged maternal hospitalization, and operative injuries. In the study of Saleh S et al15 maternal complications were; in $62 \%$ cases antepartum hemorrhage, in 17\% cases severe postpartum hemorrhage, in $30 \%$ cases necessity of blood transfusions $(p=0.002)$, in $31 \%$ cases morbid adherent placenta, in $8 \%$ cases emergency csection hysterectomy and in $4 \%$ cases maternal death ( $p=0.407)$. In comparison to our results, study conducted by Yadava PA et al ${ }^{16}$ reported that total $52 \%$ patients suffered from antepartum hemorrhage and $17.04 \%$ suffered from post-partum hemorrhage, $3 \%$ of total patients developed DIC and $2 \%$ developed acute renal failure. Similarly, our data regarding the complications of placenta previa entity is comparable to Thakkar
JK et al. ${ }^{17}$ Study conducted by Zhang $L$ et al ${ }^{18}$ reported that in subsequent pregnancy, females with a placenta previa history are at risk for negative effects including postpartum hemorrhage. Placenta previa was found to be an independent determinant for bleeding, placenta accreta spectrum (PAS) disorders and placenta previa during subsequent pregnancy in females with a history of caesarean section. Another study conducted by Lyu $B$ et al ${ }^{19}$ suggested that one prior cesarean section, two or more prior cesarean sections, anterior placenta, complete placenta previa, placenta accrete, antenatal hemoglobin $<10 \mathrm{~g} / \mathrm{L}$ and delivery prior to 34 gestational weeks were independent risk factors of peripartum hysterectomy among patients with placenta previa $(P<0.05)$.

In this study, $5.10 \%$ of females had placenta previa (type IV), $27.55 \%$ were found to have type III placenta previa, $29.08 \%$ were found to have type II placenta previa and $38.27 \%$ were found to have placenta previa type I. Similarly, Swetha $B^{20}$ reported that commonest type of the placenta previa was type one among 13 cases having previous caesarean sections out of 24 , followed by one patients had type III placenta previa and five patients each of type tow \& four respectively. On other hand Khan FM et al21 reported that placenta previa type IV was commonest among $40.0 \%$, followed by type II $31.6 \%$, placenta previa type III was $20 \%$ and type I was only $8.3 \%$ of the cases. In this study according to the maternal outcome antepartum hemorrhage was found in $95.5 \%$ of the patients. Yadava PA et al ${ }^{16}$ reported that $52 \%$ patients suffered from antepartum hemorrhage and $17.04 \%$ were found with post-partum hemorrhage. Uzma $\mathrm{S}$ et $\mathrm{al}^{4}$ also reported that antepartum hemorrhage was $54 \%$ and post-partum hemorrhage was $15 \%$. Sarojini et al ${ }^{22}$ reported that $12.7 \%$ cases were found with postpartum hemorrhage and adherent placenta was seen in $4.7 \%$ of the patients. However, we also found adherent placenta $5.10 \%$. In this series $86.7 \%$ women underwent blood transfusions, while postpartum hemorrhage was seen in $41.3 \%$ of the cases. Similarly, Sarojini et al22 stated that total $83 \%$ patients underwent blood and blood product transfusions. However, Khan FM et al ${ }^{21}$ reported that $23 \%$ patients ended up in hysterectomy and $30 \%$ underwent $\geq 10$ blood transfusions. We found renal impairment in $25.5 \%$ patients, caesarean hysterectomy $7.1 \%$ and maternal mortality $1.5 \%$. On other hand Sarojini et a ${ }^{22}$ reported that $3.8 \%$ cases had acute kidney injury and $1(0.9 \%)$ was maternal mortality. However, Yadava PA et al ${ }^{16}$ reported that out of all $3 \%$ patients developed DIC and acute renal failure was developed in $2 \%$ of the cases. In agreement of this study Uzma $S$ et $\mathrm{al}^{4}$ also reported that caesarean hysterectomy was done in $12 \%$ of the patients having placenta previa with previous cesarean section.

In the current study, NICU admission rate was $35.2 \%$ and prematurity rates were $53.1 \%$. Still birth was recorded in $27 \%$, intrauterine death in 17.9, and although the prevalence of still birth and prematurity and was strongly related to higher placenta previa degree while restricting fetal development, admission to $\mathrm{NICU}$ and intrauterine death were also insignificant among different placental grades which is analogous to the studies of Rangaswamy M et al and Maiti S et al. ${ }^{23,24}$ In the current study, 
in $14.3 \%$ cases, fetal growth suppression was found to be as an impact of placenta previa with earlier C-section on fetal outcomes. However, Adere A et al ${ }^{1}$ also observed that fetal born from placenta previa women having risk of being preterm birth, IUGR, and the respiratory distress syndrome.

\section{CONCLUSION}

Placenta previa with previous caesarean section is associated with adverse feto-maternal complications. The most frequent maternal outcome was blood transfusion and antepartum haemorrhage, likewise intrauterine growth restriction, low birth weight, intrauterine death, NICU admission and prematurity were common fetal outcomes. Placenta previa related perinatal and maternal morbidity and mortality are preventable. Efforts must be made to minimize these rates, which may be accomplished via spacing pregnancies, reducing the family size, appropriate and vigilant prenatal care, and timely referral of patients who are at high risk. To provide adequate counseling to their patients, healthcare professionals should be cautious of potential complications. This would undoubtedly assist in enhancing both mother and fetus outcomes in all the pregnancies that are at high risk.

\section{LIMITATIONS}

There were no significant limitations.

\section{SUGGESTIONS / RECOMMENDATIONS}

More multicenter studies should be done on this subject, transport facilities should be provided in basic health units for early arrival to tertiary care Hospitals. Arrangement of blood must be there of each group for emergency transfusion.

\section{CONFLICT OF INTEREST / DISCLOSURE}

There is no conflict of interests.

\section{ACKNOWLEDGEMENTS}

We acknowledge and thank to our friends and seniors, for their continuous support and guidelines.

\section{REFERENCES}

1. Adere A, Mulu A, Temesgen F. Neonatal and Maternal Complications of Placenta Praevia and Its Risk Factors in Tikur Anbessa Specialized and Gandhi Memorial Hospitals: Unmatched Case-Control Study. J Pregnancy. 2020;2020. Article ID 5630296.

2. Senkoro EE, Mwanamsangu AH, Chuwa FS, Msuya SE, Mnali $\mathrm{OP}$, Brown BG, Mahande MJ. Frequency, risk factors, and adverse fetomaternal outcomes of placenta previa in Northern Tanzania. J Pregnancy. 2017;2017:7.

3. Khan FK, Yaqoob S, Kalsoom Z. Maternal morbidity associated with repeated cesarean sections. Biomedica. 2012;28:134-7.

4. Uzma S, Kiani BA, Khan FS. Frequency of placenta praevia with previous caesarean section. Ann Pak Inst Med Sci. 2015;11(4):202-5.

5. Salihu HM, Li Q, Rouse DJ, Alexander GR. Placenta previa: neonatal death after live births in the United States. Am J Obstet Gynecol. 2003;188(5):1305-9.
6. Ananth CV, Smulian JC, Vintzileos AM. The effect of placenta previa on neonatal mortality: a population-based study in the United States, 1989 through 1997. Am J Obstet Gynecol. 2003;188(5):1299-304.

7. Ananth CV, Demissie K, Smulian JC, Vintzileos AM. Relationship among placenta previa, fetal growth restriction, and preterm delivery: a population-based study. Obstet Gynecol. 2001;98(2):299-306

8. Brace V, Kernaghan D, Penney G. Learning from adverse clinical outcomes: major obstetric haemorrhage in Scotland, 2003-05. BJOG. 2007;114(11):1388-96.

9. Bhide A, Prefumo F, Moore J, Hollis B, Thilaganathan B. Placental edge to internal os distance in the late third trimester and mode of delivery in placenta praevia. BJOG. 2003;110(9):860-4.

10. Kang J, Kim HS, Lee EB, Uh Y, Han KH, Park EY, et al. Prediction Model for Massive Transfusion in Placenta Previa during Cesarean Section. Yonsei Med J. 2020 Feb;61(2):154-160.

11. Bhuyar S, Dharmale N. Study of maternal and fetal outcome in various types of placenta previa. IJRCOG. 2018;7(11):4653.

12. Ayaz A, Farooq MU. Risk of adverse maternal and peri-natal outcome in subjects with placenta previa with previous cesarean section. Kurume Med J. 2012;59:1-4

13. Rouse DJ, MacPherson C, Landon M, Varner MW, Leveno KJ, Moawad AH, et al. National Institute of Child Health and Human Development Maternal-Fetal Medicine Units Network. Blood transfusion and cesarean delivery. Obstet Gynecol. 2006;108(4):891-7.

14. Silver RM, Landon MB, Rouse DJ. Maternal morbidity associated with multiple repeat cesarean deliveries. Obstet Gynecol. 2006;107:1226-29.

15. Saleh S, Ismaeel SK. Placenta Previa: Risk Factors, Maternal And Fetal Outcome-The Middle East Experience. Intl. J. Clin. Diag. Res. 2018;6(6):III

16. Yadava PA, Patel RR, Mehta AS. Placenta previa: risk factors, feto-maternal outcome and complications. Int $\mathrm{J}$ Reprod Contracept Obstet Gynecol 2019;8:4842-6.

17. Thakkar JK, Thakkar SJ. Study of foetomaternal outcome in cases of placenta previa. J Evolution Med Dent Sci. 2018;7(19):2329-32.

18. Zhang L, Bi S, Du L, Gong J, Chen J, Sun W, Shen X, Tang J, Ren L, Chai G, Wang Z. Effect of previous placenta previa on outcome of next pregnancy: a 10 -year retrospective cohort study. BMC Pregnancy and Childbirth. 2020 Dec;20(1):1-8.

19. Lyu B, Chen M, Liu XX. Risk factors of peripartum hysterectomy in placenta previa: a retrospective study of 3840 cases. Zhonghua fu chan ke za zhi. 2016 Jul 25;51(7):498.

20. Swetha B. Study on Association of Placenta Previa with Previous Cesarean Section Pregnancy. IOSR Journal of Dental and Medical Sciences 2016;15;5;60-63

21. Khan FM, Anwar K, Asghar S, Yousuf S. Frequency of placenta accreta in patients with placenta previa and previous $\mathrm{C}$-sections. Proceeding SZPGMI. 2015;29(1):59-62.

22. Sarojini, Malini KV, Radhika. Clinical study of placenta previa and its effect on maternal health and fetal outcome. Int $\mathrm{J}$ Reprod Contracept Obstet Gynecol. 2016;5:3496-9.

23. Rangaswamy Rangaswamy M, Govindaraju K. Fetomaternal outcome in placenta previa-a retrospective study in teaching hospital. Int J Reprod Contracept Obstet Gynecol. 2016;5(9):3081-4. 
24. Maiti S, Kanrar P, Karmakar C, Bagdi S. Maternal and perinatal outcome in rural Indian women with placenta previa. Br Biomed Bullet. 2014;2(4):714-8.

\section{AUTHORSHIP CONTRIBUTION}

\begin{tabular}{|l|l|}
\hline $\begin{array}{l}\text { Dr. Najma Bano Shaikh } \\
\text { Assistant Professor, Department of } \\
\text { Gynecology \& Obstetrics, Liaquat } \\
\text { University Hospital, Hyderabad Pakistan }\end{array}$ & $\begin{array}{l}\text { Wrote the first draft of } \\
\text { manuscript }\end{array}$ \\
\hline $\begin{array}{l}\text { Dr. Farah Naz } \\
\text { Senior Registrar, Department of } \\
\text { Gynecology \& Obstetrics, Liaquat } \\
\text { University Hospital, Hyderabad Pakistan }\end{array}$ & $\begin{array}{l}\text { Contribution in } \\
\text { manuscripts writing and } \\
\text { data collection }\end{array}$ \\
\hline $\begin{array}{l}\text { Dr. Farhana Shaikh } \\
\text { Associate Professor, Department of } \\
\text { Gynecology \& Obstetrics, Liaquat } \\
\text { University Hospital, Hyderabad Pakistan }\end{array}$ & $\begin{array}{l}\text { Literature review and } \\
\text { research guideline }\end{array}$ \\
\hline $\begin{array}{l}\text { Dr. Shahnaz Begum } \\
\text { Women Medical Officer, BHU, Bahawal } \\
\text { Zounr, Hyderabad Pakistan }\end{array}$ & $\begin{array}{l}\text { Contribution in manuscript } \\
\text { writing and data analysis }\end{array}$ \\
\hline $\begin{array}{l}\text { Dr. Shabnam Shaikh } \\
\text { Consultant Gynecologist, Hospital Shah } \\
\text { Faisal Colony Korangi Karachi Pakistan }\end{array}$ & $\begin{array}{l}\text { Literature review and } \\
\text { analysis }\end{array}$ \\
\hline $\begin{array}{l}\text { Dr. Samina Shaikh } \\
\text { Senior Registrar, Department of } \\
\text { Gynecology \& Obstetrics, Liaquat } \\
\text { University Hospital, Hyderabad Pakistan }\end{array}$ & Data analysis and \\
\hline
\end{tabular}

